Born in Boston on January 2, 1889, Prof. Adams is a graduate of Harvard University, where he received the A.B. degree in 1909 , the A.M. in 1910 and the Ph.D. in 1912. He later received the honorary degree of Doctor of Science from the Polytechnic Institute of Brooklyn, North-western University and the University of Rochester. He went abroad to study at the University of Berlin and at the Kaiser Wilhelm Institute during 1912-13. From 1913 to 1915 he was an instructor in organic chemistry at Harvard and at Radeliffe College. He joined the faculty of the University of Illinois as assistant professor in 1916, becoming a professor in 1919 and head of the chemistry department in 1926. He was a member of President Roosevelt's Science Advisory Board in 1934-35, and in World War II he served in Washington with the National Defense Research Committee. Prof. Adams is a fellow of the American Association for the Advancement of Science and was chairman of Section $\mathrm{C}$ of the Association in 1927. $\mathrm{He}$ is a member of the American Academy of Arts and Sciences and the American Philosophical Society, and an honorary fellow of the Chemical Society of London. He has been a member of the Council and chairman of the Chemistry Section of the National Academy of Sciences, and a member of the fellowship board of the National Research Council. Besides serving the American Chemical Society as president and chairman of the Board of Directors, he was a director during 1931-36 and 1940-43, and a councillor-at-large during 1923-29.

\section{Eli Lilly and Company Prize}

Dr. JoHN D. FERRY, assistant professor of chemistry in the University of Wisconsin, who developed valuable sufgical products from blood plasma during the War, Jas been given the Eli Lilly and Company Prize of 1,000 dollars awarded by the American Chemilal Society for "versatile and incisive studies on the chemistry, especially the physical chemistry, of large molecules". Besides doing war-time research on blood plasma in the Department of Physical Chemistry at the Harvard Medical School, Dr. Ferry served on a special advisory panel of the Army Quartermaster Corps on the preparation and use of plastics and films from high polymers. Dr. Ferry was born at Dawson, British Columbia, on May 4, 1912, and graduated from Stanford University; during 1932-34 he worked at the National Institute for Medical Research in London. His early work was upon the size of viruses as estimated by their passage through membranes. Studies of polyisobutylene and polystyrene and of rubber followed, leading to an interest into the properties of large protein molecules and of the mechanical properties of their gels. A photo-elastic method for the study of elasticity and rigidity of gels over a wide range of frequencies has contributed greatly to our understanding on one hand of such systems as polystyrene-xylene; on the other, of the gelation of gelatin and the clotting of blood. His knowledge of proteins in the solid state has led during the War to the production, from the proteins concerned with the natural clotting process, of fibrinogen plastic and fibrin tubes and films. Fibrin film has found acceptance in neuro-surgery as a dural substitute and is now being applied to other surgical uses. Prepared entirely from fractions of human plasma, these products approach those that occur in Nature in their physical properties, in that they do not lead to foreign body reactions, and in their ultimate fate in the body.

\section{Frof. P. van Oye}

Prof. Dr. P. VAN OYE, the leading Belgian hydrobiologist, was gixty on August 24, an event which has been duly clebrated by his numerous friends and followers other festivities, of a more official character, aye to follow shortly. Prof. van Oye can look back on more than thirty years of splendid biological work, including for a great part studies on plankton of many countries, in most cases the result of personal exhaustive and exhausting field-work; in this last respect, he most certainly can compete with the keenest of his younger followers. He wrote numerous and important papers on Desmids (on which he is one of the world's leading authorities), Rotators, Rhizopods, etc.; he is the discoverer of the periodical evolution of the plankton in tropical regions, and, together with Apsteins, of the rule on the variation of plankton-facies. Another very important discovery of his is the constancy of the $p H$ in a given aquatic biotope. Prof. van Oye spent several years in Indonesia and the Belgian Congo, and shortly before the War visited Iceland. The Biogeographical Institute, University of Ghent, has done and is doing useful work under his leadership. The patriotic attitude of Prof. van Oye under the occupation caused the Germans to relieve him of his post and even to imprison him for some weeks.

\section{New European Scientific Periodicals}

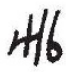

THE revival of lecientific thought in Europe has been signalleo by the reappearance of familiar journals which were suppressed during the German occupafion, an by the publication of new journals. Laf Wattye and Revue générale des sciences in France we swift to recover, and they were joined a few months ago by the new journal Atomes. A little more than a year ago, Experientia, described as a "monthly journal of pure and applied science", under the direction of A. v. Muralt, L. Ruzicka and J. Weigle, with Dr. H. Mislin as editor, was published by Verlag Birkhäuser AG. of Basle. The general language used is German; but announcements are printed in German, French, Italian and English. The contents consist of general illustrated articles (in one of the languages mentioned), followed by "brief reports" of current work corresponding to the "Letters to the Editors" in Nature, most of which have summaries in a language other than that of the 'report' itself, and book reviews, etc. The published price is 2 Swiss francs each issue plus postage. From Germany comes Zeitschrift für Naturforschung, published by Dieterich'she Verlagsbuchhandlung, Wiesbaden, by authority of the Military Government. This appeared in January of this year, under the direction of A. Sommerfeld, K. Clusius and A. Kühn, and is also a monthly journal. It contains short original articles, preliminary announcements of investigations, reviews of recent work, and news ; the whole is in German.

\section{Freedom of Intellectual Liberty}

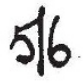

Is our age thididea of intellectual liberty is under attack from directions. On one hand, there are its theorefichl enemies, the apologists of totalitarianism fland on the other, its immediate practical engaried monopoly and bureaucracy ("The Prevention of Artrature." By George Orwell. (Polemic No. 2.) London: Rodney Phillips and Co., 1946. 2s. 6d.). The independence of the writer and the artist are being eaten away by vague economic forces and also 
undermined by those who should be its defenders. Underlying the attacks on freedom of thought and of the Press is the dangerous proposition that freedom is undesirable and that intellectual honesty is a form of anti-social selfishness. The enemies of intellectual liberty try to present their case as a plea for discipline versus individualism, leaving in the background that the issue is truth versus untruth. Totalitarianism, whether political or religious, exerts its greatest pressure on the intellectual at the point where literature and politics cross. The exact sciences are not, so far, menaced to the same extent, yet some scientific workers seem to think that the destruction of liberty is of no importance so long as their own line of work is unaffected. Even totalitarian States tolerate the scientific worker for the moment because his work is recognized by the rulers as necessary, if only to prepare for war. But when the totalitarian State will be well established, this may not be so. If, therefore, the man of science would guard the integrity of science, he should develop some kind of solidarity with his literary colleagues. In Great Britain, broadly speaking, there is liberty ; but there is the sinister suggestion that the conscious enemies of liberty are those to whom liberty ought to mean much. 516

\section{R.C.A. Review}

All those concernga yith radio research and development will weledn the reappearance, after a four-yeq interval, of tA R.C.A. Review, a technical journal focorling progress in radio and electronics rescheh and angmeering as described by scientific workers, endheers and executives of the Radio Corporation of America. The March 1946 issue forms the first number of volume 7 ; and in an introduction thereto General David Sarnoff, president of the Radio Corporation of America, explains that the new R.C.A. Review is written by men of science and engineers not only to relate their past achievements but also to reflect the thoughts of those whose pioneering in research, development and engineering are projecting the present into the future. The eight papers in the present issue cover a variety of subjects relating to television, navigation and radio telegraphic signalling by change of frequency in contrast with on-off keying. The experimental results obtained in the development of omni-directional radio beacons for aerial navigation are described in a paper by D. G. C. Luck, of which the first two parts were published in 1941 and 1942. Another paper, by I. F. Byrnes, discusses the possibilities of a shipboard radar installation as an aid to navigation for the mercantile marine. The development of the image orthicon tube for an extremely sensitive television camera is described by R. D. Kell and G. C. Szikali of the Research Dept., R.C.A. Laboratories; while some of the results obtainable by the use of this camera for field television operation are dealt with by R. E. Shelby and H. P. Lee, of the National Broadcasting Company, Inc. Short biographical notes with photographs of all the contributors form an infyesting appendix to this publication.

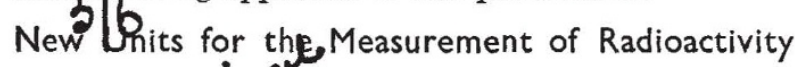

Two new unito the 'rutherford' and the 'roentgenper-hour atpone metre' for the measurement of radioaqtifily, have recently been recommended by the Natfonal Bureau of Standards, at the suggestion of the Committee on Radioactivity of the National Research Council. The Radiology Congress in
Brussels in 1910 defined the curie as "the amount of radon in equilibrium with one gram of radium". Therefore, strictly speaking, the curie can only be used to represent the disintegration-rate of radium or its equilibrium products. As is pointed out by E. U. Condon and L. F. Curtiss (Rev. Sci. Instr., 17, 249 ; June 1946. Also Phys. Rev., 69, 672; June 1946), it has, however, become the custom to use the curie, quite erroneously, as the unit of strength of all radioactive sources. The disintegration. rate, which correctly specifies the strength of a radioactive source, is a pure number, and is determined by the decay constant and the number of atoms of the radioactive isotope in the source. All that is required, therefore, to establish a proper unit, is to choose a suitable number, preferably a multiple of ten. The number $10^{6}$, with the name 'rutherford', abbreviated to 'rd.', is recommended. No confusion can arise when dealing with the radium family, as the curie and rutherford are sufficiently different in magnitude. Apart from that of definition, the rutherford has other advantages over the curie. The rutherford is a definite unit, whereas the curie is uncertain to at least 4 per cent, and also, the new unit does away with the necessity for measuring radio-isotopes in terms of a standard. For the intensity of gamma-ray sources, it is recommended that a roentgen-per-hour at one metre be used in place of the curie. The abbreviation, 'r.h.m.', pronounced 'rum', is suggested. A gamma-ray source of one r.h.m. has a gamma-ray strength of the same order of magnitude as that of one curie of radium.

\section{A Thermal Eyepiece forpene Telescope $\$ / 6$}

AN article with wits title by H. P. Wilkins, an assiduous obserof the moon, who recently produced a 300-in tunal map appears in Sky and Telescope of May. Hr. 'Wilkins has made a 'thermal eyepiece' fil. chables the heat of the moon to be noted fis why when it is inserted in the focus of his $12 \frac{1}{2}$-in. Notonian reflector. The instrument consists of a very small light couple suspended between the poles of a permanent magnet, one junction of the couple being at the focus of a positive eyepiece of orthoscopic or monocentric type. It is necessary to suspend the couple freely, and hence in the case of an equatorial mounting the tube or eyepiece should rotate. The apparatus is enclosed in a brass case which fits into the sliding eyepiece tube like an ordinary eyepiece. The couple is made from strips of copper and constantan, and the suspension is a very fine quartz thread. Full directions are given about the use of the instrument, the principle of which depends upon the fact that the thermo-electric current produced by the heat of the moon causes the loop to turn in the field of the permanent magnet, and it is possible to judge the relative intensities of radiation from various portions of the lunar surface. The apparatus can be shielded from the heat of the body by interposing a non-conducting sheet of wood or asbestos. Interesting results have been obtained during lunar eclipses, the turning moment of the couple diminishing before the encroachment of the umbra and being reduced to zero during totality. During penumbral eclipses, when the sun, as seen from the moon, appears partially eclipsed by the earth, a diminution of the heat from the moon is noticed. It seems possible for most amateurs with a small mechanical equipment to construct one of these instruments, though many details must be attended to; these are dealt with very fully in the article. 